\title{
Concentración y homogeneidad socioeconómica: representación de la segregación urbana en seis ciudades intermedias de Chile
}

\section{Concentration and socioeconomic homogeneity: representation of urban segregation in six intermediate cities of} Chile.

\section{Fernando Toro* y Hernán Orozco**}

Recibido: 30 de marzo de 2018

Aceptado: 16 de junio de 2018

\section{Resumen}

El presente artículo tiene como objetivo analizar el estudio de fenómenos de homogeneidad y polarización asociados a la segregación urbana en seis ciudades intermedias chilenas: Iquique - Alto Hospicio, Antofagasta, La Serena - Coquimbo, Rancagua - Machalí, Talca y Temuco - Padre Las Casas. Metodológicamente el estudio de caso será abordado a través de la comparación entre la representación cartográfica de la segregación urbana tradicional (Grupos socioeconómicos predominantes) y una propuesta de representación de homogeneidad socioeconómica a partir de la desviación estándar entre los porcentajes de cada grupo. Entre los resultados transversales de la investigación, se destaca la presencia de: 1) heterogeneidad socioeconómica en los centros urbanos principalmente a través de grupos $\mathrm{C} 2$ y $\mathrm{C} 3$, con presencia $A B C 1$ y $D$ en algunos casos particulares; 2) homogeneidad social en las periferias urbanas, destacando los grupos $A B C 1$ y $C 3$ y; 3 ) emplazamiento de los grupos socio económicos bajos en zonas cuyas barreras geográficas limitan su acceso a la centralidad.

Palabras clave: ciudades intermedias, crecimiento urbano, desigualdad urbana, homogeneidad social, segregación residencial.

\begin{abstract}
The present article aims to analyze the study of homogeneity and polarization phenomena associated with urban segregation in six Chilean intermediate cities: Iquique - Alto Hospicio, Antofagasta, La Serena Coquimbo, Rancagua - Machalí, Talca and Temuco - Padre Las Casas. Methodologically, the case study will be approached through the comparison between the cartographic representation of traditional urban segregation (predominant socioeconomic groups) and a proposal of representation of socioeconomic homogeneity based on the standard deviation between the percentages of each group. Among the crosssectional results of the research, the presence of: 1) socio-economic heterogeneity in urban centers mainly through groups $\mathrm{C} 2$ and $\mathrm{C} 3$, with presence of $A B C 1$ and $D$ in some particular cases; 2 ) social homogeneity in urban peripheries, highlighting groups $A B C 1$ and $C 3$ and; 3) location of low socio-economic groups in areas whose geographical barriers limit their access to centrality.

Keywords: intermediate cities, residential segregation, social homogeneity, urban growth, urban inequality.
\end{abstract}

* University College London, London, United Kingdom. Contacto: fernando.cano.17@ucl.ac.uk

** Universidad Tecnológica Metropolitana, Santiago, Chile. Contacto: horozco.r@utem.cl

Los autores agradecen al Programa de Master's Fellowship de la Lincoln Institute of Land Policy.

Cómo citar: Toro, F. y Orozco, H. (2018). Concentración y homogeneidad socioeconómica: representación de la segregación urbana en seis ciudades intermedias de Chile. Revista de Urbanismo, 38, 1-21. http://dx.doi.org/10.5354/0717$\underline{5051.2018 .48834}$ 


\section{Introducción}

La Segregación Residencial Socioeconómica (en adelante SRS), entendida como la separación espacial de los distintos Grupos Socioeconómicos (en adelante GSE) y como el abandono del Estado en cuanto a las necesidades de los grupos más vulnerables situados de forma concentrada en ciertas áreas de la ciudad, es una de las consecuencias espaciales y territoriales más estudiadas de la desigualdad urbana en Chile.

Entre sus causas de carácter interno se encuentra la mercantilización del suelo derivado de la liberalización económica nacional postdictadura y los altos precios del suelo central y pericentral (López-Morales, 2015; Tapia, 2011) que ha entregado a los supuestamente competitivos mercados la tarea de ordenar la ciudad, los usos y las supuestas decisiones de localización de las familias. Lo anterior, se relaciona directamente con las causas externas derivadas de la globalización económica y cultural de las últimas décadas (Sabatini \& Brain, 2008) y la competencia entre las ciudades por entrar en circuitos globales de inversión y maximización de la rentabilidad inmobiliaria (Smith, 1996; Sassen, 1991), en desmedro de los derechos a la vivienda y la ciudad.

Entre sus consecuencias se encuentran el aumento de la escala geográfica de la SRS a un nivel metropolitano, por el desplazamiento de la población más vulnerable a las periferias de las configuraciones urbanas en Latinoamérica (Rodriguez \& Arriagada, 2004). En Chile particularmente, se ha generado un proceso masivo de periferización de la vivienda social (Hidalgo, 2007) amparado en una política habitacional enfocada en el déficit cuantitativo (Rodríguez y Sugranyes, 2005), la elitización de los barrios centrales, el desplazamiento por exclusión de las clases bajas de las áreas centrales (LópezMorales, 2013), y la auto-segregación de las elites económicas en barrios periféricos cerrados (Sabatini, Mora, \& Polanco, 2013).

Esta multiplicidad de causas y consecuencias ha generado un debate académico en los últimos años sobre la SRS, en vías de entregar propuestas de solución o mitigación, entre quienes creen que el problema es la baja proximidad física de los distintos estratos socioeconómicos (Sabatini et al., 2010) y los que creen en la necesidad de cambios estructurales en el modelo de desarrollo urbano para evitar el abandono del Estado de los grupos más vulnerables en cuanto a sus necesidad de infraestructura, equipamiento y servicios urbanos de calidad (Ruiz-Tagle \& López, 2014; Rodríguez \& Winchester, 2005).

Ambas visiones coinciden en la relevancia del Estado y las acciones intersectoriales necesarias para disminuir los procesos de SRS. De igual forma, han abordado tangencialmente la homogeneidad socioeconómica, o concentraciones espaciales del mismo estrato, en términos de tamaño y localización principalmente de los grupos vulnerables. Además, estos enfoques se han traducido en tímidos despliegues de políticas públicas contra la SRS, como, por ejemplo: la dispersión subsidiada de la vivienda social, los subsidios de vivienda para grupos medios paras que se localicen en comunidades con grupos mayormente vulnerables, o el mejoramiento de la calidad y la accesibilidad a infraestructura de movilidad, bienes y servicios urbanos. No obstante, no se ha producido una política pública que cuestione los altos niveles de homogeneidad social, y que incluya en la solución del problema, la disminución de la autosegregación de los grupos de clases altas, los cuales aportan a la fragmentación simbólica del espacio urbano (ver Marcuse, 1989).

A pesar de que esta investigación busca cuestionar la aseveración de que la proximidad de grupos sociales similares en el espacio agrava ciertos problemas sociales, es importante para el estudio de la segregación, hacer mención de conceptos útiles que constituirán la base para el análisis del presente artículo. De acuerdo a Sabatini (2006), se pueden diferenciar tres conceptos de interés, el primero de ellos, es la concentración de grupos socioeconómicos en el espacio que dice relación con la predominancia de ciertos grupos en ciertos sectores de la ciudad y que se ha graficado a través de representaciones cartográficas (Figura 1). 


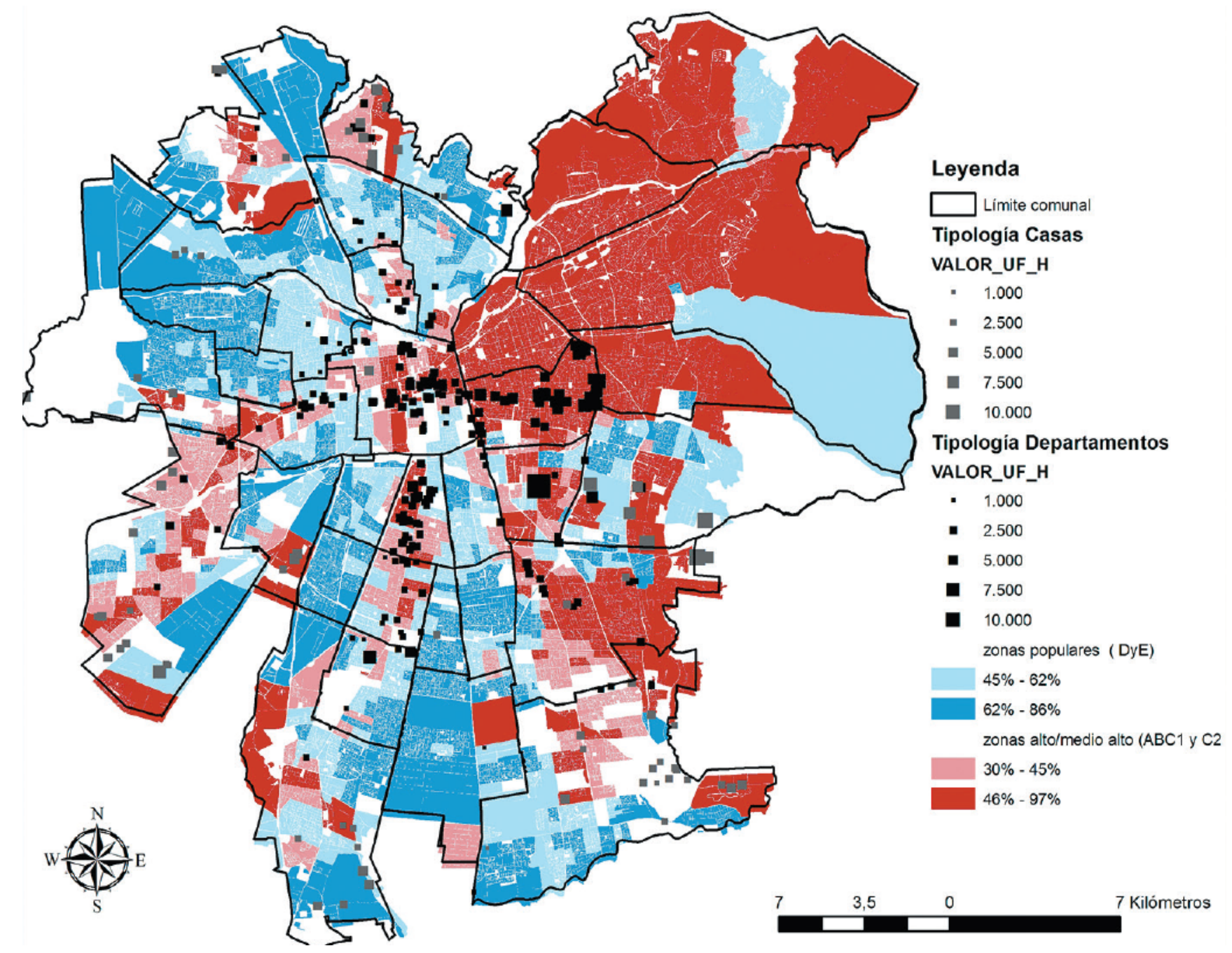

Figura 1. Catastro de proyectos inmobiliarios Gran Santiago 2014 sobre zonas censales populares (D y E) y estratos altos/medios altos (ABC1 y C2).

Fuente: Sabatini, Rasse, Cáceres, Robles y Trebilcock, 2017.

Son estas representaciones las que la presente investigación pone en cuestión por resultar incompletas para describir el fenómeno de la segregación, por ende, se propone complementar la información mediante la descripción y análisis de lo siguientes conceptos tratados por Sabatini (2006): la homogeneidad socioeconómica entendida como el nivel de diferenciación entre los estratos de los hogares de una unidad de espacio determinada, y la polarización socioespacial que dice relación con la separación en el espacio y a escala de la ciudad de los grupos mayormente homogéneos de distintos estratos socioeconómicos, sobre todo, de aquellos más vulnerables respecto de los más acomodados (Sabatini, 2006).
Por otro lado, la investigación de la SRS en Chile ha tenido un desarrollo considerable en las áreas metropolitanas como Santiago, Valparaíso o Concepción (Link, Valenzuela \& Fuentes, 2015; Sabatini et al, 2010; Sabatini, Cáceres \& Cerda, 2001), pero un bajo desarrollo en lo que respecta a este tipo de procesos y sus impactos en ciudades intermedias (Letelier \& Boyco, 2010). Lo anterior no se condice con la relevancia política y científica que han adquirido estos contextos en los últimos años ( Maturana \& Rojas, 2015; Hidalgo et al, 2009), en este sentido, se debe considerar que las ciudades intermedias tienen sus propias complejidades en términos de la segregación, la dualidad entre la presión del crecimiento urbano y el impacto de las actividades productivas extractivas (Borsdorf, Sánchez, \& Marchant, 2008), y la compleja intermediación entre estas y sus diferentes 
escalas asociadas con los gobiernos locales y central (Salazar, Irarrázaval \& Fock 2017).

Las ciudades intermedias se presentan como una oportunidad para desarrollar propuestas de planificación y gestión que permitan ciudades mayor integración en el futuro (Espinoza et al, 2016; Letelier \& Boyco, 2010; Borsdorf, Sánchez \& Marchant, 2008, CEPAL, 1998), considerando que sus habitantes tienen una mayor predisposición positiva a la mezcla de clases sociales en comparación con las ciudades metropolitanas (Sabatini et al., 2012).

En este contexto, se considera importante establecer ¿cuál es el estado de segregación y la homogeneidad socioeconómica en las ciudades intermedias en Chile? y ¿cuáles son los grupos socioeconómicos mayormente concentrados? ¿cuál es su relación entre estos grupos y la estructura de cada ciudad?

De esta forma, es importante profundizar el estudio de la SRS en ciudades intermedias reconociendo que éstas poseen una mayor tasa de crecimiento sostenido en los últimos años en comparación con las ciudades metropolitanas (Borsdorf, Marchant \& Sánchez, 2012) y existe un debate por las características de los futuros "gobiernos metropolitanos" que surgirán tras la aprobación de la Ley de Fortalecimiento de la Regionalización que permitirá la elección popular de la principal autoridad regional y la creación de áreas metropolitanas por parte de estas autoridades. Así, se configura un objetivo específico de este trabajo, que es graficar la SRS en distintas ciudades intermedias chilenas para determinar factores comunes y diferencias.

El objetivo del presente trabajo es analizar la distribución socioeconómica de la población en el territorio para las ciudades de Iquique - Alto Hospicio, Antofagasta, La Serena - Coquimbo, Rancagua - Machalí, Talca y Temuco - Padre Las Casas, comparando los estratos socioeconomicos predominantes y la homogeneidad socioeconómica en cada manzana, a través de dos formas de representación cartográfica de datos censales.

\footnotetext{
${ }^{1}$ Los bienes por los que se consulta son: Tv Color, Refrigerador Teléfono fijo, Teléfono celular, Videograbador, Horno microondas, TV cable, Automóvil uso particular, Computador y Conexión a internet.
}

Este estudio busca aproximarse a las condiciones de segregación ubana de estas ciudades, permitiendo identificar algunos factores diferenciadores, y determinando ciertas coincidencias y contrastes bajo la hipótesis de que estas ciudades expresan rasgos de homogeneidad social o concentración de determinados grupos socioeconómicos y polarización.

\section{Metodología}

El presente artículo se basa en el procesamiento de los datos censales del año 2002 (INE, 2002),como muestra inicial, la que fue expandida mediante la contabilización de viviendas y caracterización de nuevos sectores residenciales a nivel nacional el año 2011 (en el proceso precensal del fallido censo del año 2012). Estos datos, son los últimos disponibles a nivel de manzana para el desarrollo de este tipo de análisis y permiten establecer la cantidad de hogares por cada uno de los grupos socioeconómicos $(A B C 1, C 2, C 3, D, E)$ propuestos metodológicamente por ADIMARK (1999) en cada una de las manzanas de las ciudades estudiadas.

Las preguntas utilizadas para construir el Índice de Estratificación Socioeconómica, en la versión antes mencionada son: (1) ¿cuál es el nivel educacional más alto alcanzado o el nivel educacional actual de la persona que aporta el ingreso principal del hogar?, y (2) ¿Posee algunos de los siguientes bienes? ${ }^{1}$.

En base a las respuestas de estas preguntas, y su ordenamiento jerárquico, se definen 5 grupos con hogares distribuidos bajo los siguientes porcentajes: $10 \%$ de los grupos de mayor ranking corresponden a $A B C 1,20 \%$ de grupos C2, 25\% de grupos C3, 35\% de grupos D, y finalmente $10 \%$ de los hogares de menor ranking que corresponden a grupos $\mathrm{E}$. Esta estratificación se trata de una de las formas más usadas en estudios de mercado y sociológicos en Chile, aunque cabe mencionar que se trata de construcciones teóricas derivadas de las directamente variables medidas, que además están en constante revisión y ajuste.

Esta información se grafica en cada una de las manzanas en cada una de las ciudades de estudio 
mediante dos formas: la primera de ellas corresponde a la representación del grupo socioeconómico predominante en cada manzana, es decir, se grafica el estrato socioeconómico que tiene la frecuencia más alta dentro de los datos de porcentajes de hogares (Método 1 en la Tabla 1). Es esta la forma más utilizada de representar cartográficamente la estratificación socioeconómica en Chile, la que a su vez, permite entender la segregación como la separación de los grupos sociales y a aumentar los niveles de estigmatización en aquellos sectores que concentran los estratos más bajos.

La segunda forma, corresponde a la representación gráfica de la desviación estándar ${ }^{2}$ entre los porcentajes de los hogares de cada uno de los estratos socioeconómicos en cada manzana, como una propuesta que permite poner el foco en la homogeneidad social como el principal problema asociado a la SRS, evitando la estigmatización y permitiendo observar la generación de enclaves de clase alta igual de significativos en la fragmentación de la ciudad que las concentraciones de estratos bajos. Lo anterior tiene el fin de avanzar hacia una mayor cuantificación de la medición de este fenómeno a nivel territorial y social tal como lo propone Catalán (2017).

Cabe mencionar que la simbolización de estas últimas cartografías se realiza mediante 5 grupos diferenciados en base a quiebres naturales (cortes de Jenks ${ }^{3}$ ) de los datos de todas las ciudades en estudio y luego aproximados a valores múltiplos de 5, quedando los siguientes tramos: entre 0 y 15 (Alta Heterogeneidad), entre 15 y 20, entre 20 y 25 , entre 25 y 35, y entre 35 y 40 (Alta Homogeneidad). Lo anterior, permite una representación gráfica legible y clara, y, por lo tanto, la comparabilidad entre cartografías.

A continuación, se presentan algunos ejemplos hipotéticos de los cálculos y métodos antes mencionados:

Tabla 1. Ejemplos de cálculo de homogeneidad por manzana

\begin{tabular}{ccccccc}
\hline & ABC1 (\%) & C2 (\%) & C3 (\%) & D (\%) & E (\%) & Estrato predominante \\
Método 1 & Desviación estándar \\
Método 2
\end{tabular}

Fuente: elaboración propia.

La comparación entre estas dos formas de representación permite generar un diagnóstico cualitativo del estado de segregación urbana existente en las ciudades intermedias antes nombradas y como la homogeneidad urbana aporta al análisis.

\footnotetext{
2 Medida estadística de dispersión de datos, el cual representa el promedio de las diferencias entre cada uno de los datos y la media aritmética del conjunto de los datos. Llevado al presente estudio, una desviación estándar de 40 implica que existe sólo un tipo de estrato en esa manzana, y por lo tanto, se trata de una manzana de máxima homogeneidad; mientras un desviación estándar de 0 corresponde a una manzana que tiene $20 \%$ de los hogares de cada uno de los estratos, y por lo tanto, mínima homogeneidad.
}

\section{Elección de los casos de estudio. Las Ciudades Intermedias}

El debate sobre las ciudades intermedias ha estado en los últimos años asociado al factor del número de habitantes. En este sentido, se puede hacer mención a dos parámetros para definirla. A nivel internacional, según 
ONU-HABITAT (2012) en países cuya población está entre las 10 y 20 millones de personas (Como en el caso de Chile), las ciudades intermedias tienen entre 70 mil y 350 mil habitantes; mientras que a nivel nacional la Ordenanza General de Urbanismo y Construcción (principal reglamento urbanístico chileno) define sólo a las ciudades metropolitanas como aquellas que superan los 500.000 habitantes.

En este contexto se considerarán como ciudades intermedias a seis áreas urbanas (que pueden tener más de una comuna) con más de 70.000 habitantes y menos de 500.000, a saber: Iquique-Alto Hospicio, Antofagasta, Coquimbo-La Serena, Rancagua-Machalí, Talca y Temuco - Padre Las Casas. Si bien las conurbaciones nombradas no constituyen áreas metropolitanas reconocidas actualmente, estas se eligieron debido a la alta tasa de crecimiento que presentan según las estimaciones del Instituto Nacional de Estadísticas (INE) y la posibilidad de que en la próxima década se constituyan como áreas metropolitanas. Es importante situarse en un escenario donde probablemente varias de estas no sólo superen los 500.000 habitantes en los próximos años, sino que también, se conurben debido a su tendencia de crecimiento.

Las ciudades intermedias chilenas no sólo poseen una mayor tasa de crecimiento que las ciudades metropolitanas (Tabla 2), sino que también a nivel mundial experimentan una tendencia de crecimiento que ha aumentado en los últimos años (Molinatti, 2013). Este fenómeno, sobre todo en países de administración centralizada como Chile, debe ser considerado urgente en cuanto a la expansión y cobertura de las redes e infraestructura en términos físicos, y además en las complejidades demográficas que en términos sociales significan (Borja, 2012).

Tabla 2. Tasa de crecimiento 2012-2020: Áreas metropolitanas y ciudades chilenas.

\begin{tabular}{|c|c|c|c|}
\hline & Población 2012 & $\begin{array}{l}\text { Población } 2020 \\
\text { (Proyección INE) }\end{array}$ & Tasa de crecimiento 2012 - 2020 \\
\hline Gran Santiago & 6.293 .414 & 7.002 .300 & 1.34 \\
\hline Gran Valparaíso & 930.217 & 1.041 .900 & 1.43 \\
\hline Gran Concepción & 958.722 & 1.034 .740 & 0.96 \\
\hline Iquique - Alto Hospicio & 278.251 & 319.300 & 1.73 \\
\hline Antofagasta & 378.933 & 423.957 & 1.93 \\
\hline La Serena - Coquimbo & 412.586 & 514.300 & 2.79 \\
\hline Rancagua - Machalí & 276.527 & 325.800 & 2.07 \\
\hline Talca - San Clemente - Maule & 286.141 & 353.799 & 2.69 \\
\hline Temuco - Padre las casas & 339.664 & 442.200 & 3.35 \\
\hline
\end{tabular}

Fuente: elaboración propia en base a datos de proyección del INE 


\section{Resultados}

A continuación, se muestran los resultados obtenidos en cada una de las ciudades estudiadas para luego analizar algunos resultados transversalmente.

Iquique - Alto -Hospicio. Este conglomerado urbano localizado en la Región de Tarapacá, corresponde a una unidad funcional, aunque no una conurbación propiamente tal, debido a que las condiciones geográficas no permiten una conurbación física entre las dos comunas por la presencia del farellón costero. En la actualidad, Iquique cuenta con poco más de 190.000 habitantes y alrededor de 67.000 viviendas (Censo, 2017), mientras Alto Hospicio, alcanza los 108.000 habitantes y las 33.000 viviendas (Censo, 2017).

De acuerdo a la Figura 2., se observa una fuerte segregación en cuanto al estrato socioeconómico predominante, observándose en Iquique, una graduación de norte a sur y un cambio socioespacial paulatino desde los estratos medio bajos del sector más antiguo de la ciudad, los cuales tradicionalmente, han albergado distintos estratos socioeconómicos y un gran número de migrantes nacionales e internacionales (Labbé, 2014). Los sectores de clase media y media alta, están asociados a los nuevos proyectos inmobiliarios desarrollados en la ciudad.

Mientras, en la comuna de Alto Hospicio (Figura 2) se observa una predominancia casi completa de los sectores más vulnerables de la población (E), con escasos sectores caracterizados por grupos de estrato medio bajo (D y C3). La representación de la homogeneidad socioeconómica de esta ciudad genera nuevas observaciones. Por un lado, en la comuna de Iquique se observa una homogeneidad alta en gran parte de su área urbana, salvo en sus últimas zonas de crecimiento de estratos altos al extremo sur (Bajo Molle), sector que ha crecido en base a condominios y edificios cerrados con una baja cobertura de equipamiento y servicios urbanos sobre todo de carácter públicos. En Alto Hospicio, en tanto, se observa una mayor heterogeneidad, a pesar de la predominancia de los estratos bajos, justamente en torno a los servicios urbanos y los equipamientos del área central de la comuna. Lo anterior, evidencia la importancia de estos elementos urbanos no residenciales en la segregación urbana y en la generación de áreas urbanas homogéneas.

En definitiva, se observan que en la ciudad de Iquique se presenta una alta heterogeneidad de grupos C2, C3 y D; y en Alto Hospicio una alta homogeneidad de grupos $D$ y $E$ principalmente.

Antofagasta. Esta ciudad es la principal área urbana de la comuna de Antofagasta, la que a su vez es la capital de la región homónima. Alberga mas de 378.000 habitantes con un poco más de 112.000 viviendas (Censo, 2017).

Hoy, la ciudad se ha convertido en un área urbana compleja. Su economía está basada en los ingresos de las actividades extractivas mineras, pero también en los servicios y el mercado inmobiliario (Daher, 2003). Lo anterior, junto a las condiciones de vulnerabilidad a ciertas condiciones geográficas desfavorables como el ancho litoral acotado y la presencia de zonas de remociones en masa y aluviones, han sido los principales motores de las condiciones de segregación urbana residencial debido a la libre transacción de suelo sin regulación por parte del Estado (Thodes, 2016).

En la cartografía de GSE predominante (Figura 3) se observa cómo la gradiente de estratificación orienteponiente es notoria, con una mayor predominancia de estratos medios altos y altos en el borde costero de la comuna, de estratos medios en la planicie litoral y de estratos medios bajos y bajos en contacto directo con el farellón costero y las condiciones de riesgo que este conlleva. Aunque cabe mencionar que algunos sectores de estratos altos igualmente están sujetos a la condición de riesgo por efectos de maremotos o tsunamis.

Esta estratificación, que por distancia podría considerarse como una forma de integración (entre borde costero y farellón costero la distancia es baja), sucede en paralelo a la polarización de los estratos más bajos y más altos. Los primeros concentrándose en el sector norte de la ciudad, tradicionalmente denominado "La Chimba", y los segundos, concentrados en las partes de más reciente desarrollo urbano (condominios cerrados) al extremo sur de la comuna, como lo son Coviefi y Jardines del Sur. 

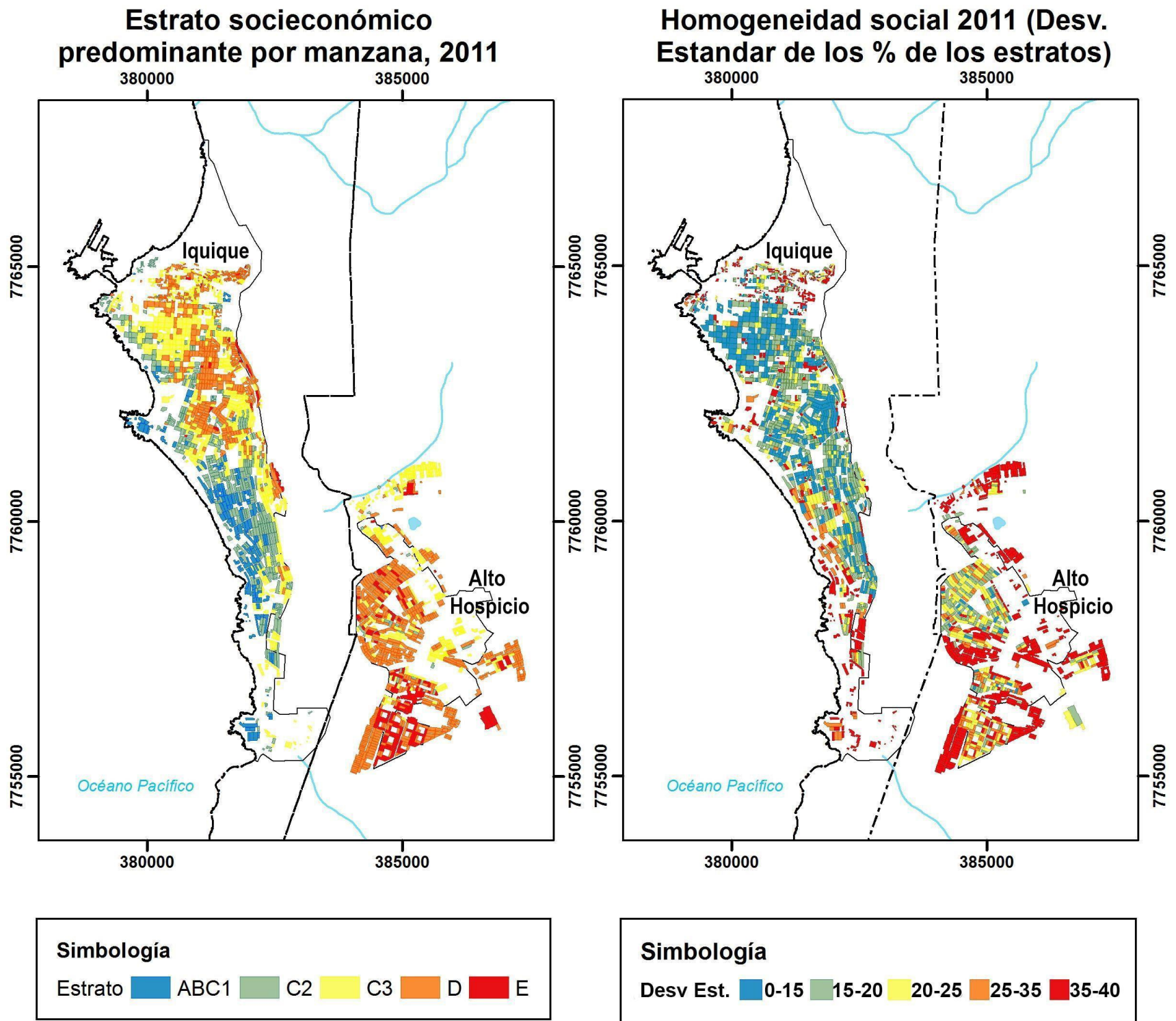

\section{Simbología}

Desv Est. $\square 0-15 \square 15-20 \quad 20-25 \square 25-35 \square 35-40$

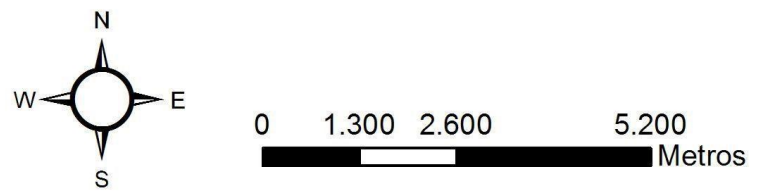

Datos Cartográficos: Sist. de Proyección: WGS 1984 Huso: 19S

Figura 2. Estrato predominante y homogeneidad social, Iquique - Alto Hospicio. Fuente: Elaboración propia en base a Censo 2002 y precenso 2011.

Por otro lado, si bien existe una alta heterogeneidad general a lo largo del territorio, esta polarización socioeconómica queda en evidencia al observar la cartografía de homogeneidad social (Figura 3), la cual muestra una heterogeneidad alta en el área central, media en las zonas de bajos ingresos adyacentes al borde del farellón costero (oriente de la ciudad), y sectores de alta homogeneidad en el extremo sur y norte, hacia donde se está expandiendo la ciudad con proyectos habitacionales con una débil regulación estatal.

En resumen, en Antofagasta la homogeneidad social está relacionada con la expansión de la ciudad, por un lado, de sectores bajos ingresos en el norte y de altos ingresos en el sur. 
El caso de Coquimbo - La Serena. Esta conurbación de dos comunas que conforman el área urbana más importante de la Región de Coquimbo alberga actualmente cerca de 450.000 personas (227.730 en Coquimbo y 221.054 en La Serena) y alrededor de 180.000 viviendas (87.464 en Coquimbo y 89.499 en La Serena) según los estadísticas del Censo de población de 2017, por lo tanto, no solo estaría pronta a cumplir con los requisitos normativos para convertirse en un área metropolitana, sino que también comenzando a evidenciar conflictos urbanos asociados a dicha escala (Daher, 2016)

A nivel de Grupos socioeconómicos (Figura 4), en lo que respecta a las áreas de concentración de estratos bajos, se observa que estas están concentradas en los extremos del área urbana, en los sectores de Parte Alta en Coquimbo (extremo poniente) y en el sector Las Compañías en La Serena (extremo norte). A lo anterior se suman algunas zonas como Tierras Blancas en Coquimbo y La Antena en La Serena donde predominan los GSE C3, D y E.

Debido a esta condición, estos sectores han sido por años foco de intervención estatal de diferente tipo e intensidad (MINVU, 2007) que van desde planes de regeneración de espacios públicos y gestión social como Quiero Mi Barrio hasta planes especiales de seguridad, lo que a su vez ha generado cierto grado de estigmatización debido a la connotación negativa que han adquirido estos barrios por las mismas condiciones mencionadas, pero también por la promoción de ellas. Respecto a los GSE más altos, estos están ubicados en la zona costera de La Serena, donde se ha observado una excesiva privatización y densificación (Orellana et al., 2016)

Al mismo tiempo, los instrumentos de planificación urbana vigentes en ambas comunas, permitieron que el desarrollo económico de la última década en la ciudad se tradujera en la extensión urbana que permitió la conurbación de la ciudad, estableciendo condiciones para el crecimiento entre los centros de ambas comunas en los sectores del borde costero y los sectores interiores denominados Peñuelas, San Joaquín y El Milagro. En estos sectores intermedios se observa la predominancia de los GSE más altos de la ciudad, casi sin existencia de estratos bajos entre manzanas.

Lo anterior, a diferencia de Antofagasta, queda comprobado al observar la alta homogeneidad social de la intercomuna (Figura 4), y que en oposición a lo que generalmente se relaciona, es considerablemente menor en los sectores previamente descritos como de concentración de ingresos bajos y medios-bajos. Se comrpueba que en los centros de estas configuraciones tanto en el sector de Las Compañías (La Serena) como en la Parte Alta (Coquimbo), existe mayor heterogeneidad que va desde la clase media a la clase más baja, coincidiendo con los sectores de mayor déficit habitacional y menor valor de suelo, algo que se repite en todos los centros urbanos de las ciudades intermedias estudiadas (Toro, 2014).

Con estos análisis es posible confirmar los altos niveles de homogeneidad de esta ciudad, que cerca de convertirse en una configuración de escala metropolitana, comienza a evidenciar niveles de homogeneidad que sólo es posible detectar en ciudades como Santiago y Valparaíso, lo que además confirma lo expuesto anteriormente sobre este tipo de ciudades, como una oportunidad urgente de frenar los procesos de segregación urbana residencial.

Finalmente, otro aspecto a relevar es la segregación intracomunal que se observa al sur de la comuna de Coquimbo, con los sectores de Punta Mira (concentración de viviendas de interés social) y el sector de la Bahía de La Herradura en el borde costero (sector de viviendas unifamiliares de estratos altos) que a pesar de estar a pocos kilómetros de distancia se han transformado en enclaves de homogeneidad media y alta. 
Estrato socieconómico predominante por manzana, 2011
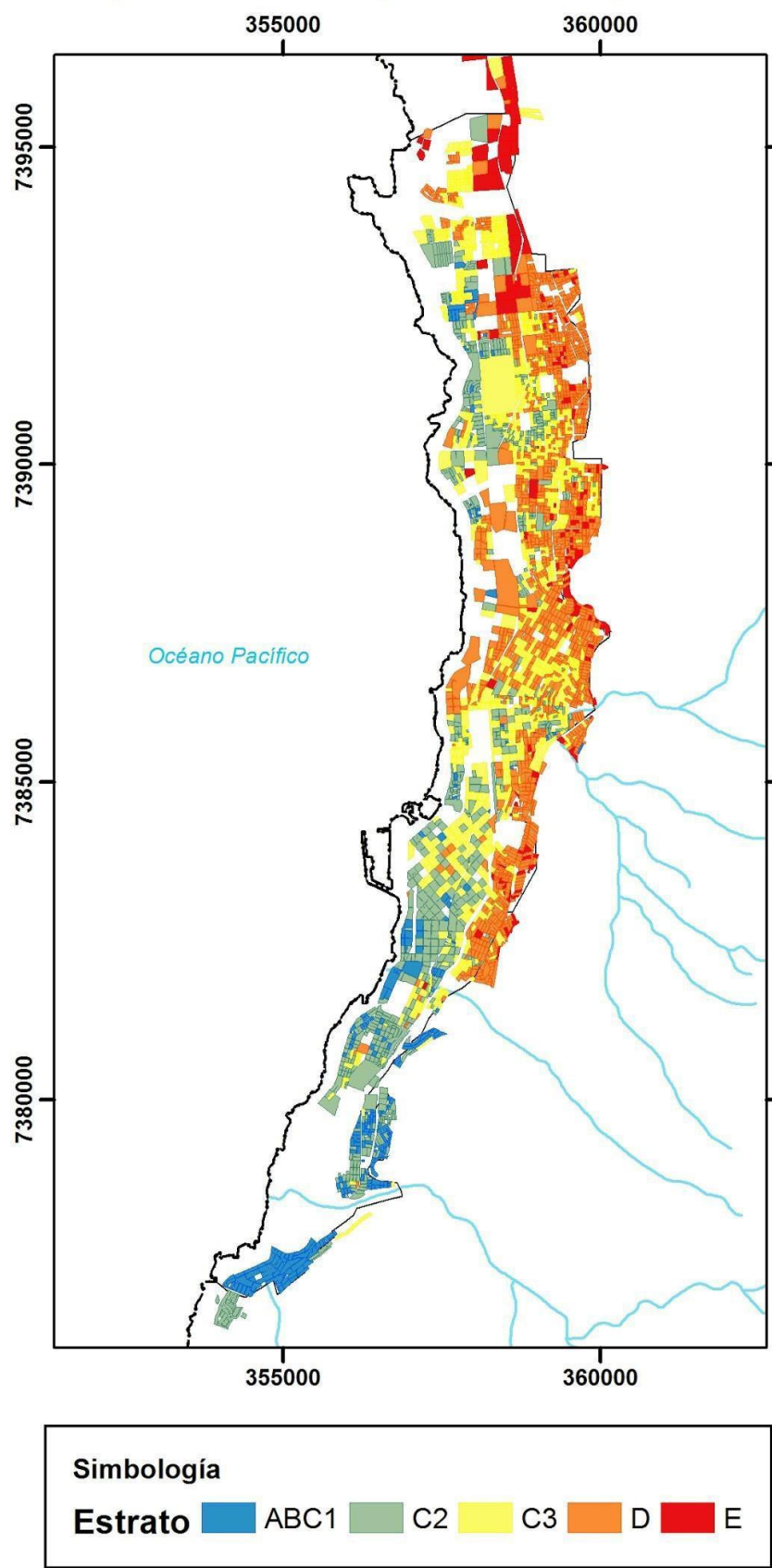<smiles>N=C1C(=N)C(=O)C(S)C1=N</smiles>

$\begin{array}{ccc}0 & 1.450 \quad 2.900 & 5.800 \\ & \text { Metros }\end{array}$
Homogeneidad social 2011 (Desv. Estandar de los \% de los estratos)

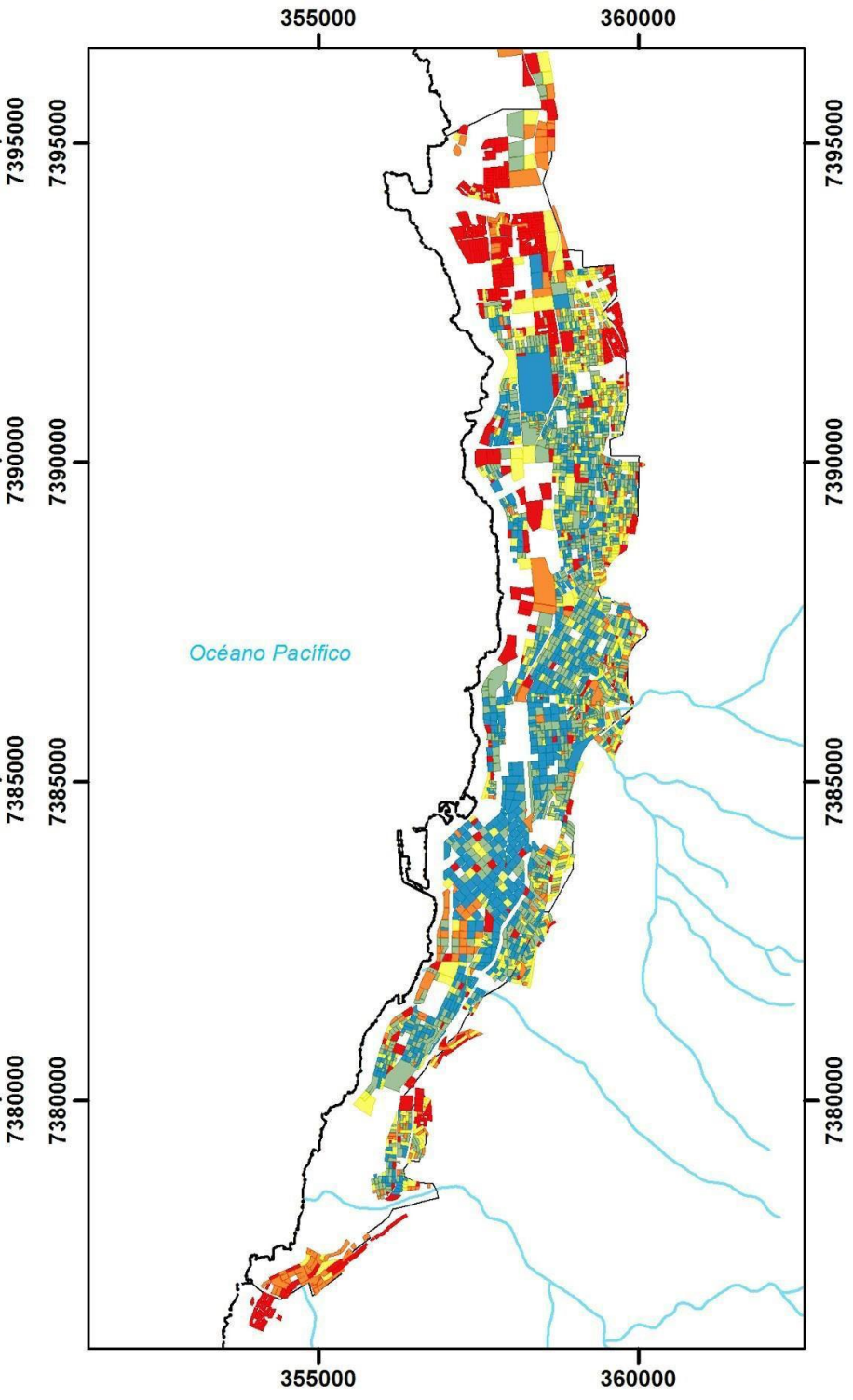

Simbología

\begin{tabular}{l|l|l|l|l|l|} 
Desv Est. $\square 0-15$ & $15-20$ & $20-25$ & $25-35$ &
\end{tabular}

Datos Cartográficos: Sist. de Proyección: WGS 1984 Huso: 19S

Figura 3. Estrato predominante y homogeneidad social, Antofagasta. Fuente: Elaboración propia en base a Censo 2002 y precenso 2011. 

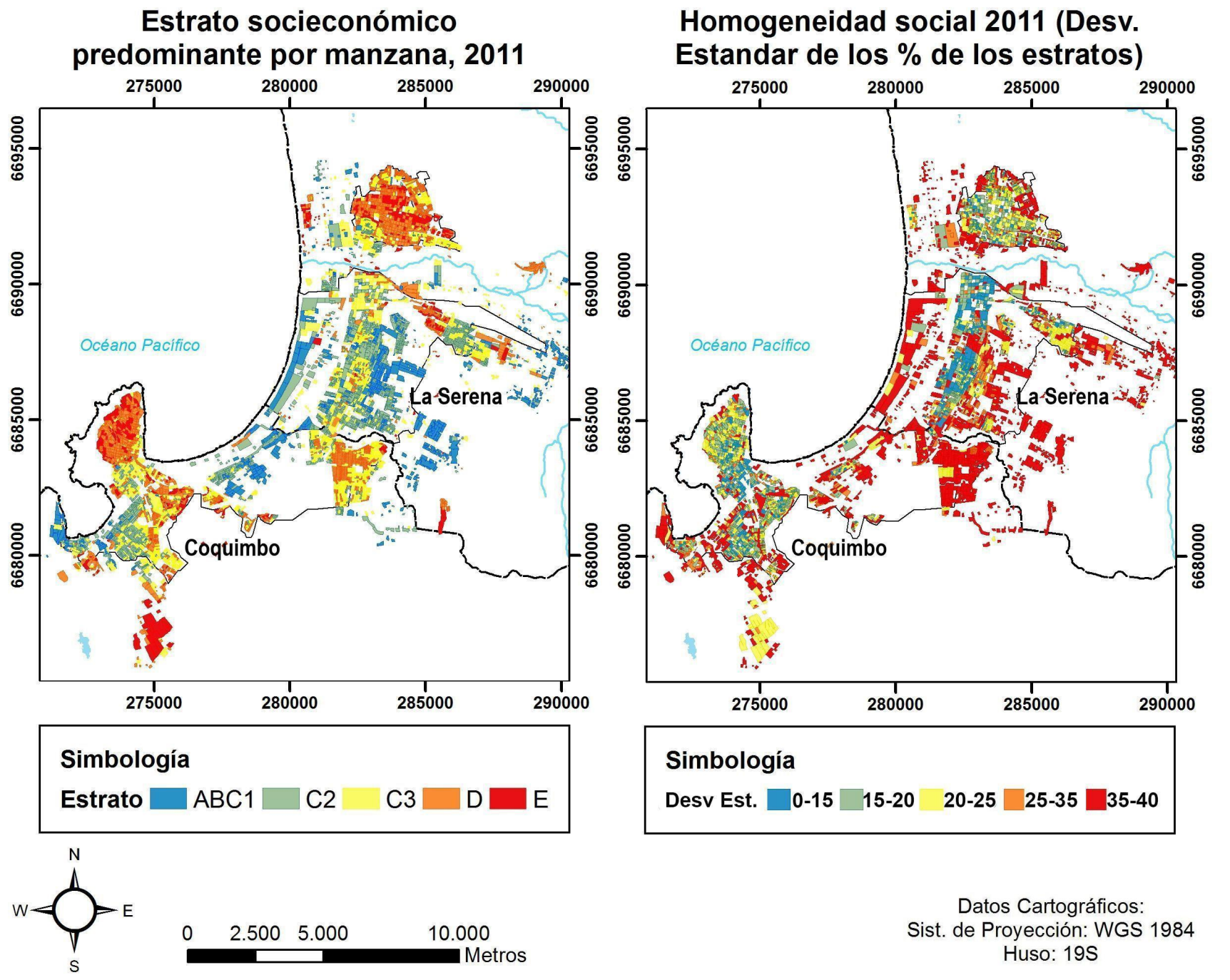

Figura 4. Estrato predominante y homogeneidad social, Coquimbo - La Serena. Fuente: Elaboración propia en base a Censo 2002 y precenso 2011.

Rancagua - Machalí. Este conglomerado urbano ad portas de convertirse en una conurbación se compone de dos comunas, esta vez de diferente tipo y tamaño. La de mayor importancia político-administrativa y población es el área urbana de Rancagua, capital de la Región de O'Higgins (octava región de norte a sur del país, y contigua a la Región Metropolitana de Santiago, capital nacional, por el sur), la cual alberga 241.774 habitantes en 90.043 viviendas (Censo, 2017); y la segunda corresponde a Machalí, comuna ubicada entre la cordillera de los Andes y Rancagua, de carácter preferentemente rural hasta hace algunas décadas y que hoy ya alberga 52.505 habitantes y 19.701 viviendas.
El crecimiento de la ciudad de Rancagua se explica primero por el auge minero de las primeras décadas del siglo XX y luego el desmantelamiento de los campamentos mineros de la región en la década de los 60 y 70 (Arenas, González y Aliaga, 2009), y más recientemente, por la consolidación de un centro urbano sus equipamientos y servicio. El crecimiento reciente de Machalí responde a la expansión periférica de la comuna anteriormente descrita, específicamente de viviendas de alto estándar que se han conurbado lentamente con el centro tradicional de la comuna.

Como se observa en los GSE predominantes (Figura 5), existen sectores de estratos bajos adyacentes a sectores de estratos altos al oriente de Rancagua (separados por la 
Av. Miguel Ramírez), además de un amplio sector de clases medias (C2 y C3) hacia el sur poniente de la comuna. Por otro lado, los sectores de vivienda dispersa entre Rancagua y el centro de Machalí, se caracterizan por el predominio de los estratos más altos a excepción del sector central de esta comuna (Santa Teresa), donde con una heterogeneidad relativa conviven conjuntos de vivienda social y nuevos conjuntos de hasta UF 5.000 (Arancibia, 2014) y del sector de Nogales, que a un costado de la carretera del Cobre se constituye como el sector con más alto GSE.

Esta descripción, muestra ciertas condiciones atípicas como es la cercanía de los estratos más extremos en la ciudad (baja polarización), pero otras que son similares a las otras ciudades intermedias como el crecimiento por extensión fragmentado para los distintos estratos sociales incluso entre clases medias y altas.

A pesar de lo anterior, las condiciones de heterogeneidad social son relativamente baja si se considera lo observado en cuanto a la homogeneidad social (Figura 5), que muestra justamente baja heterogeneidad en toda la periferia de la conurbación, la cual cuenta con distintos estratos predominantes. Por una parte los sectores medios muy concentrados en la periferia nor-poniente, los sectores de estrato alto muy concentrados en el sector poniente y los estratos bajos concentrados principalmente en el sector sur.

Por otro lado, los centros de ambas comunas son poco homogéneos, lo que parece ser una norma para las ciudades intermedias, donde más allá de los estratos socioeconómicos predominantes, la heterogeneidad es regularmente alta.

En conclusión, en este caso se vuelve a verificar la alta heterogeneidad en los centros y la alta homogeneidad ligada a la expansión urbana (bordes) como queda en evidencia en los casos anteriores. Finalmente, aparece el GSE C3 como un grupo que se concentra al oeste en forma de condominios y proyectos sociales.

El caso de Talca. La ciudad de Talca es la principal área urbana de la comuna homónima, la que a su vez es la capital regional de la Región del Maule. Actualmente la comuna alberga poco más de 220.000 personas en más de
80.000 viviendas (Censo 2017). Esta ciudad es la primera de las ciudades en análisis que debe su desarrollo al auge de la actividad agrícola exportadora de la región (Maragaño, 2009), lo que además ha impactado fuertemente en su paisaje o imagen urbana menos densa y mayormente natural (Rodríguez \& Carrasco, 2016).

En cuanto a lo que se puede observar en la configuración de la estratificación por predominancia es interesante constatar la clara distinción entre los estratos en la ciudad, con un centro dominado por grupos de clase media y media alta (C3 y C2), con un sector sur del área mayormente consolidada de estratos bajos ( $D$ y $E$ ) en los sectores denominado El Mirador y Sur Oriente, y una periferia oriente de características semiurbanas (condominios y loteos con terrenos de grandes dimensiones de tipo cerrado) en que predominan los estratos más altos.

En este caso, se repite el patrón de sectores dominados por los GSE más bajos adyacentes a los estratos más altos, siendo las clases medias (C3) las que se concentran a los extremos norte y sur de la ciudad respecto de estas últimas. Especialmente en este caso, es necesario también realizar un análisis con información más actualizada, puesto que el terremoto del 2011 tuvo diversas consecuencias en la configuración urbana ligadas principalmente a la gentrificación de población hacia las periferias urbanas (Letelier \& Boyco, 2013; Inzulza, 2014), modificando el panorama espacial y social de la ciudad.

En relación con la homogeneidad social (Figura 6), es posible observar un fenómeno similar al constatado en Rancagua y Machalí, donde los sectores antes mencionados como predominantes de estratos bajos son los que tienen una heterogeneidad alta.

Nuevamente es el crecimiento de la ciudad el que se transforma en el principal motor de la segregación por homogeneidad social, siendo un patrón reconocible en la homogeneidad de los sectores de clase media y la autoexclusión del espacio urbano de los estratos más altos de la sociedad que se refugian en condominios cerrados que aprovechan la laxitud de los instrumentos de planificación urbana, lugares casi solo conectados a través del uso del automóvil privado. 


\section{Estrato socieconómico predominante por manzana, 2011}

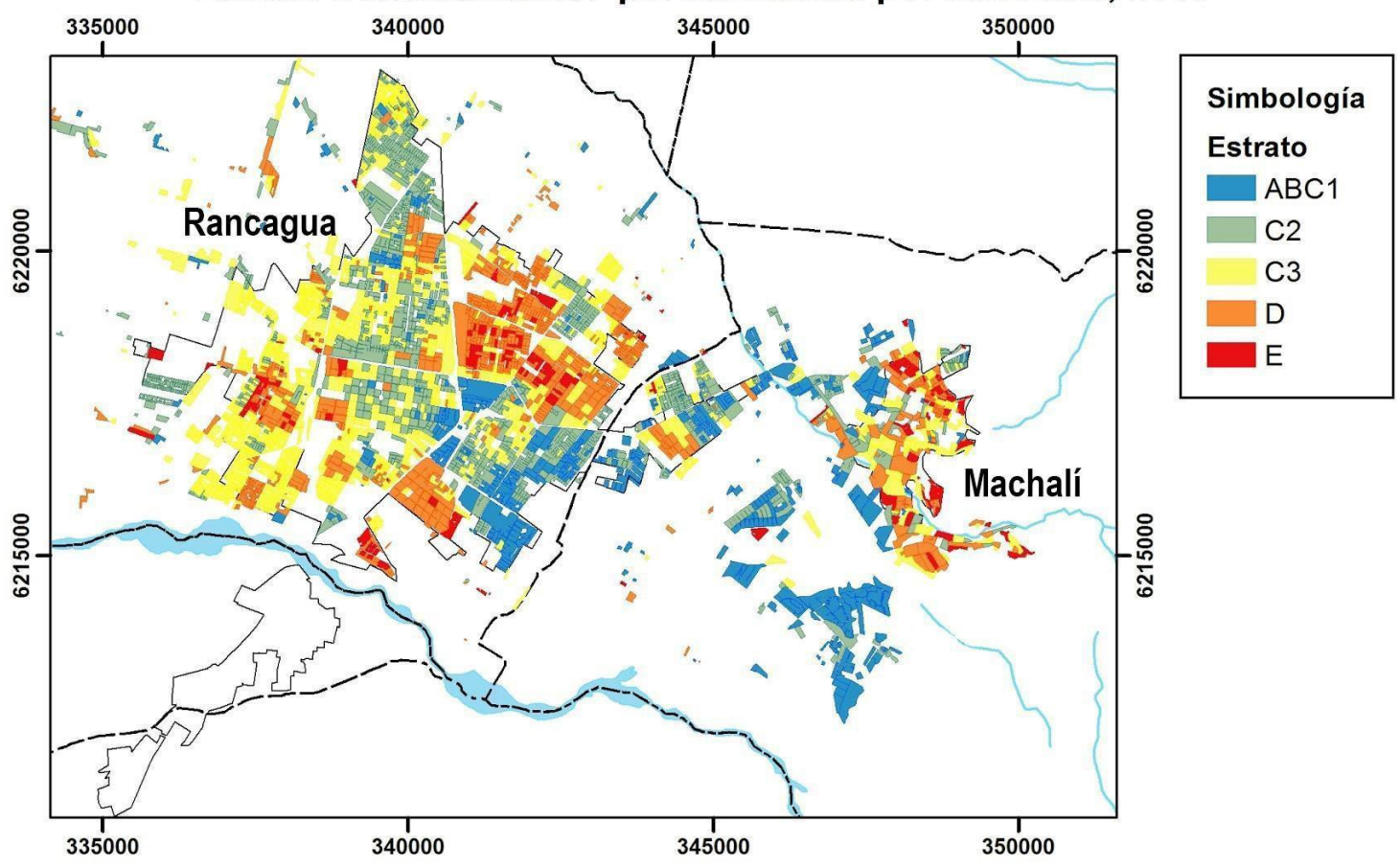

Homogeneidad social 2011 (Desv. Estandar de los \% de los estratos)

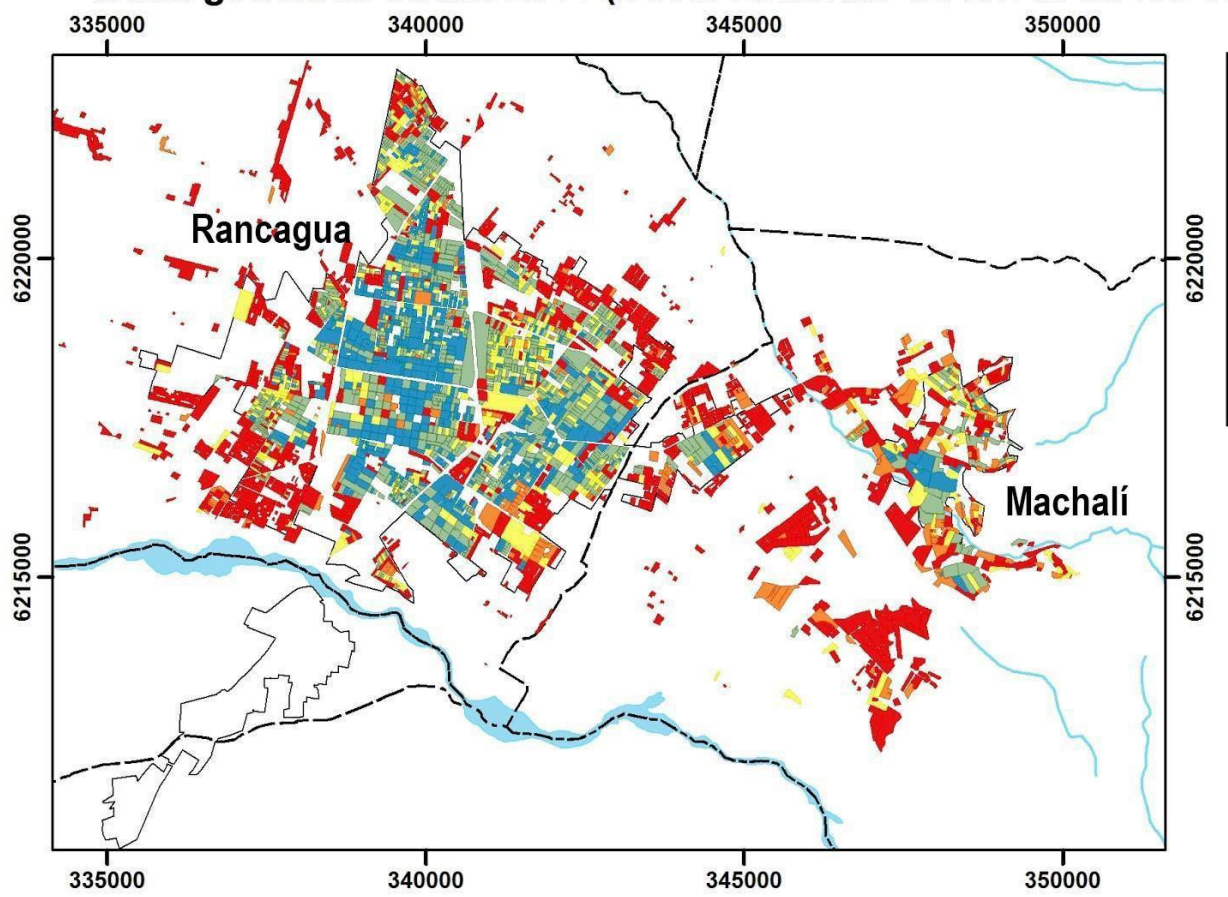

Simbología

Desv. Est.

$0-15$

15-20

20-25

25-35

$35-40$

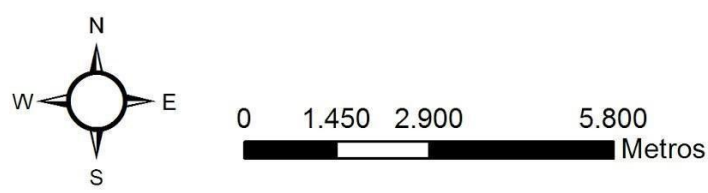

Datos Cartográficos: Sist. de Proyección: WGS 1984 Huso: 19S

Figura 5. Estrato predominante y homogeneidad social, Rancagua - Machalí. Fuente: Elaboración propia en base a Censo 2002 y precenso 2011. 


\section{Estrato socieconómico predominante por manzana, 2011}
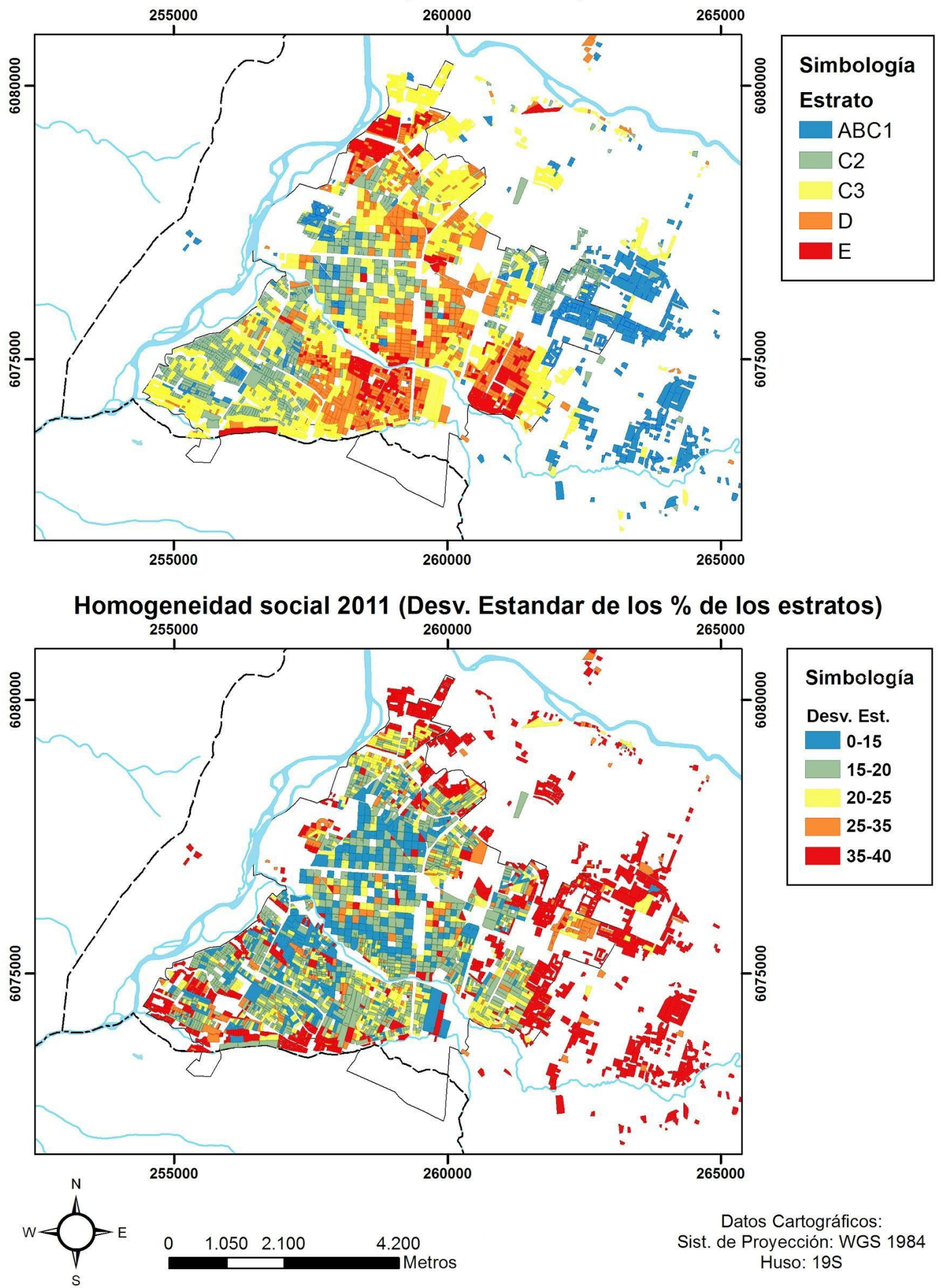

Figura 6. Estrato predominante y homogeneidad social, Talca.

Fuente: Elaboración propia en base a Censo 2002 y precenso 2011. 
El caso de Temuco - Padre Las Casas. Esta conurbación se compone de dos comunas con disímiles características. La primera de ellas es la comuna de Temuco, la que data de principios de finales del siglo XIX y que basó, en un comienzo, su crecimiento en la fuerte actividad productiva forestal de la Región de la Araucanía y, actualmente,en la consolidación de una economía terciaria producto de la asignación de la ciudad como capital (Garín, Salvo \& Bravo, 2009) de la Región de la Araucanía); actualmente la comuna de Temuco alberga 282.415 habitantes y 104.757 viviendas (Censo, 2017).

La segunda comuna en cuestión corresponde a Padre Las Casas, que nace de la división político-administrativa de la comuna anteriormente descrita en el año 1996, con un carácter preferentemente residencial enfocada en viviendas para estratos medios y bajos, hoy ha superado los 76.000 habitantes y las 26.000 viviendas (Censo, 2017). Históricamente el límite comunal entre ambas, el río Cautín, fue un elemento estructurador de la segregación urbana; albergando a su alrededor, tanto en las orillas sur como norte, a la población más vulnerables de la ciudad (Garín, Salvo \& Bravo, 2009).

Este patrón rige a la fecha, si se observa que la gran cantidad de superficie en que predominan los estratos bajos en una de las regiones con los mayores índices de pobreza, se concentran en los bordes el río (Figura 7), tanto en Temuco en los barrios de San Antonio, Santa Rosa y Amanecer, como en Padre Las Casas incluyendo principalmente el centro de la ciudad. Además, es reconocible también entre los barrios donde predominan los estratos bajos el extremo norte de la ciudad de
Temuco en el sector denominado Pedro de Valdivia. La relación de SRS ligada al río no sólo es respecto de su cercanía, sino que también respecto de la comuna, siendo Padre las Casas una comuna con ausencia de GSE ABC1 y c2.

Por su parte, las manzanas donde predominan los estratos medio-altos se concentran en el sector centro de la ciudad, mientras los estratos más altos se localizan en el sector poniente de la ciudad y en menor medida de forma dispersa en la periferia oriente. Por su parte los grupos medios (C3) parecen estar dispersos por toda la ciudad entre las concentraciones de los demás estratos. En términos de segregación en esta región, aparecen también como fundamentales aspectos como la vialidad, crecimiento urbano e interculturalidad (Salazar et al., 2017).

Por otro lado, al observar la homogeneidad social de la conurbación (Figura 7) se distingue que el centro de la conurbación y los centros urbanos menores como es el de Padre Las Casas tienen niveles de heterogeneidad alta, sectores que en este caso incluyen las áreas de mayor vulnerabilidad de la comuna como son los barrios antes mencionados como de estratos bajos. Además de lo anterior, en Temuco nuevamente se repite el patrón de periferias de estratos medios y altos con mayores niveles de homogeneidad.

Finalmente, nuevamente se observa una tendencia que demuestra que la homogeneidad se ubica en las zonas de expansión urbana, predominantemente por GSE C3 tanto en Temuco como Padre Las Casas. 


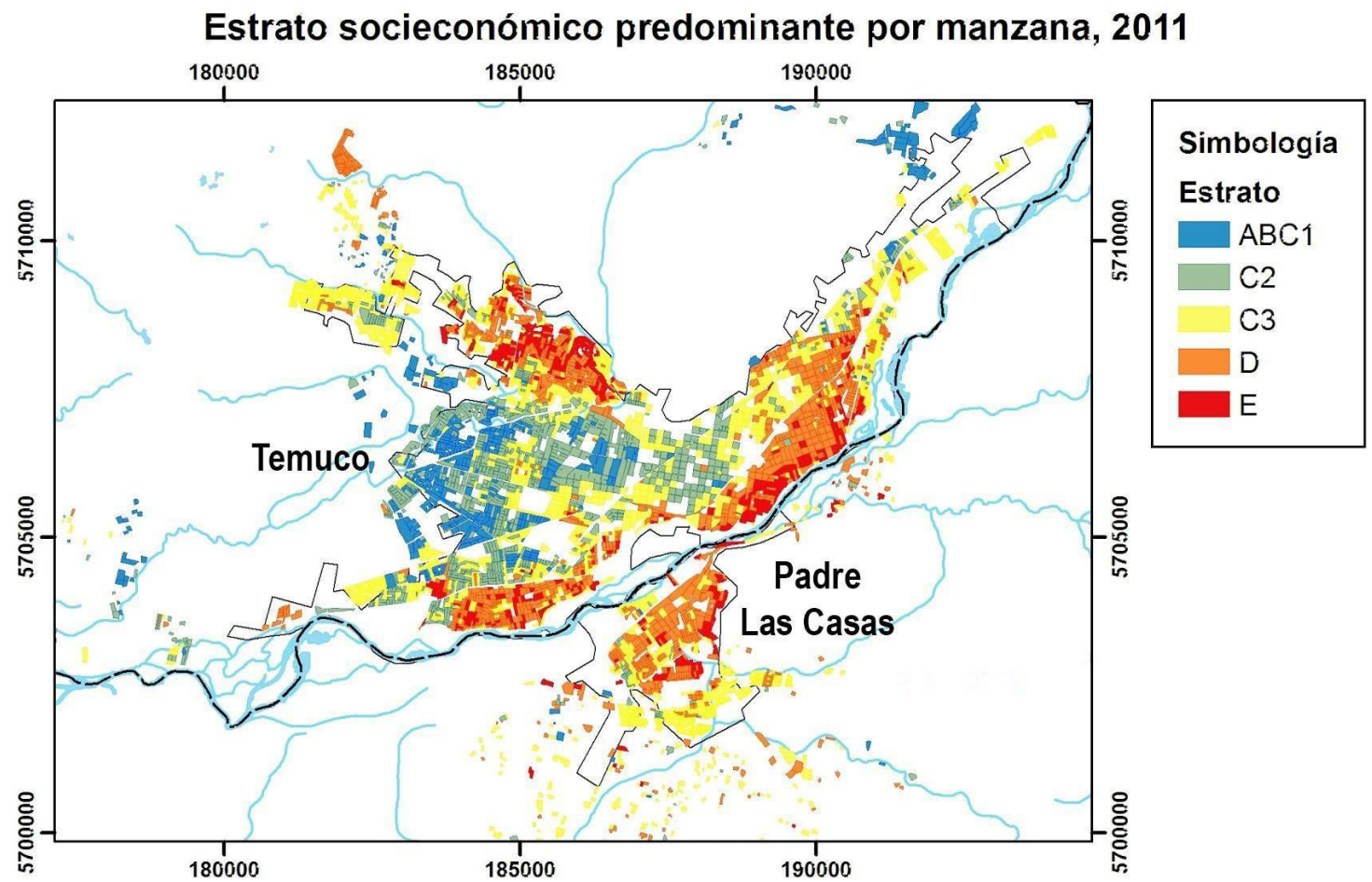

Homogeneidad social 2011 (Desv. Estandar de los \% de los estratos)

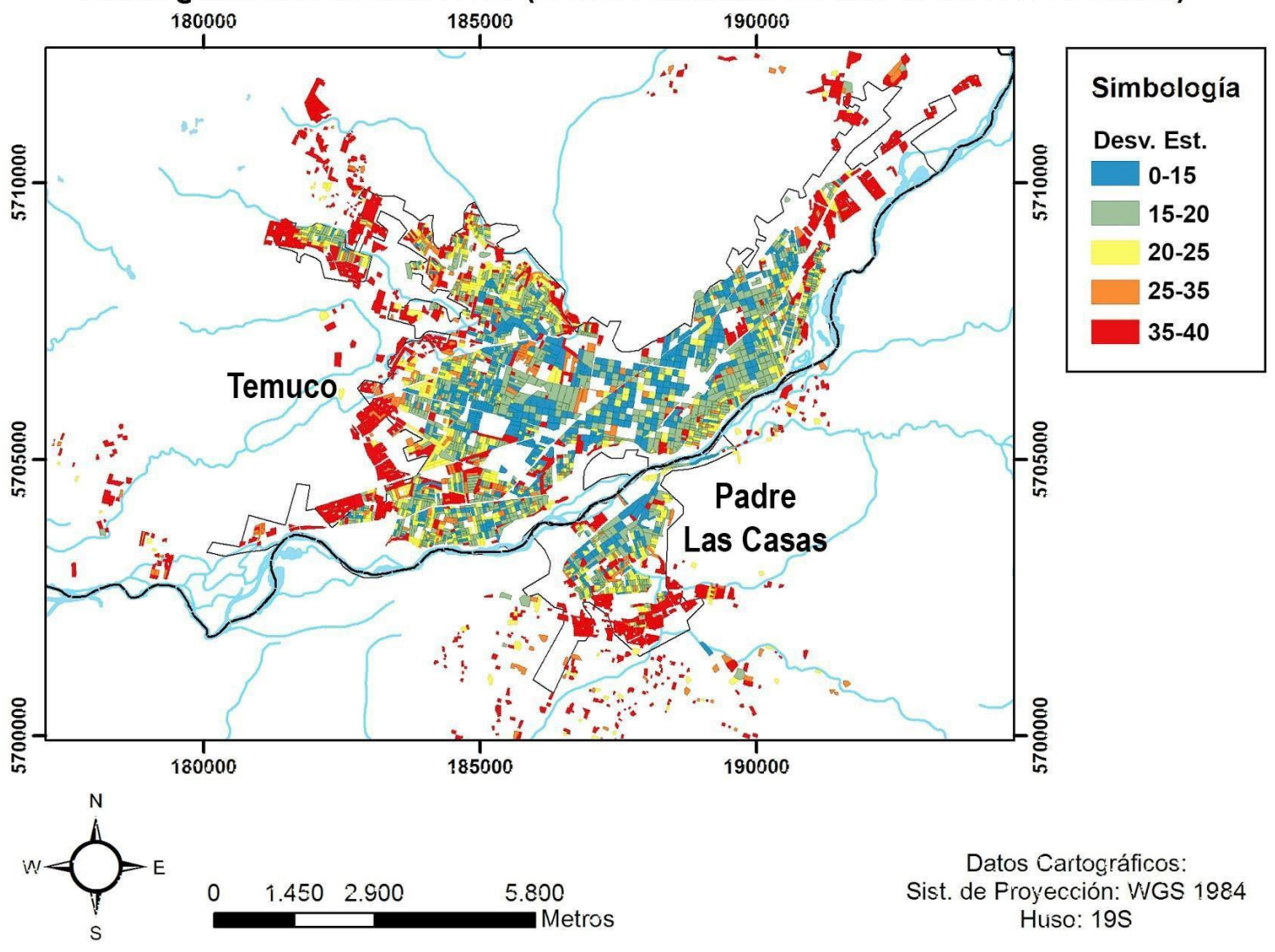

Figura 7. Estrato predominante y homogeneidad social, Temuco - Padre Las Casas.

Fuente: Elaboración propia en base a Censo 2002 y precenso 2011. 


\section{Discusión de resultados}

En una primera aproximación, el análisis de distribución de los grupos socioeconómicos confirma la hipótesis de similitudes entre las ciudades intermedias y muestra cómo existen dos tendencias de localización principales para los sectores de estratos altos ( $A B C 1$ y $C 2$ ). Por un lado, se han consolidado en barrios de relativa cercanía al centro de las ciudades estudiadas de forma medianamente concentrada aprovechando los niveles de bienes y servicios urbanos que permiten las centralidades urbanas, y por otro lado, han manifestado una tendencia a la periferización, con una posible automarginación, en base a condominios cerrados absolutamente homogéneos.

En este sentido cobra importancia la discusión abierta en torno a las responsabilidades de las empresas inmobiliarias y los productos inmobiliarios en la segregación de la ciudad, sin que esto signifique que el Estado no tenga responsabilidades concretas en la segregación residencial urbana de medianas y grandes ciudades. Considerando además que esta situación es mayormente evidente en las ciudades estudiadas de mayor tamaño como La Serena - Coquimbo, Antofagasta e Iquique - Alto Hospicio. Lo anterior, plantea un Ilamado a reflexionar sobre si ¿es tarde para la planificación con enfoque de integración de estas ciudades intermedias ad portas de convertirse en áreas metropolitanas?

En contraste, las zonas de estratos bajos tienen una mayor variedad de tendencias de localización y niveles homogeneidad en la ciudad, sin que esto signifique que sean situaciones derivadas de las preferencias de estos grupos. En el sentido de esto último, es posible referirse a casos como el del sector Las Compañías en la Región de Coquimbo, Alto Hospicio en la Región de Tarapacá y, Padre Las Casas en La Araucanía, sectores que se ubican separados de las áreas centrales por los accidentes geográficos más importantes de sus respectivas cuencas como son el Río Elqui, el farellón costero y el Río Cautín, respectivamente, configurando situaciones de vulnerabilidad socioambiental.

No obstante, cabe mencionar que, a pesar de esta condición de vulnerabilidad de los sectores antes mencionados, es posible observar que estos tienen un grado importante de heterogeneidad social, similar a los sectores de estratos bajos de las áreas centrales de
Iquique o del centro de Rancagua que se han consolidado como sectores de alta heterogeneidad social.

Otra generalidad para estas ciudades intermedias, que surge a partir del análisis cualitativo de la visualización de las cartografías presentadas, es la polarización de los estratos bajos respecto de los estratos altos, pero también una tendencia a la separación en el espacio de los estratos medios con los dos antes mencionados. No se puede dejar de constatar como una amenaza la homogeneidad social que han alcanzado muchas de las zonas que concentran los estratos medios, así la repulsión tradicional entre los estratos más bajos y más altos estaría siendo extrapolada a la relación entre las clases bajas y medias, y de las altas con las medias, una posible hipersegregación que sería interesante abordar en futuras investigaciones.

Lo anterior se evidencia si se considera la distancia entre las concentraciones de los estratos predominantes y se corrobora al estudiar la homogeneidad de las periferias urbanas o áreas de crecimiento reciente, siendo éstas los principales focos de homogeneidad social. Respecto de esto mismo, es posible consignar que tanto en Rancagua como en Talca la polarización aún no se presenta como un fenómeno consolidado, pudiendo ser una característica de ambas ciudades de característica concéntrica, a diferencia de Iquique, Antofagasta y Coquimbo-La Serena de una expresión más lineal por su condición geográfica.

En contraste a estas periferias homogéneas, se considera que los centros de las conurbaciones estudiadas siguen manteniendo altos grados de heterogeneidad, lo que significa una oportunidad en términos de mitigar la segregación, pero al mismo tiempo pudiese ser un -espejismo de integración producto de los procesos de gentrificación incipientes que comienzan a ser estudiados en ciudades como lquique (Labbé, 2014) y Talca (InzulzaContardo, 2014).

En favor de establecer a la homogeneidad de los centros de estas ciudades intermedias como una oportunidad, está la constatación de que la generación de nuevas centralidades en base a planes de regeneración y el mejoramiento de barrios, parece permitir aumentar la homogeneidad en estos sectores intervenidos por el Estado, como por ejemplo en Las Compañías en La Serena o Alto Hospicio en Tarapacá, reflejando así, la importancia de la inversión pública, la regulación del suelo y las 
políticas públicas en general, como factores de integración.

\section{Conclusiones: Aportes y desafíos}

Con las limitaciones metodológicas que se presentan debido a la ausencia de datos censales recientes, y a través del análisis transversal de las ciudades, esta investigación contribuye y abre la discusión sobre los desafíos futuros, en las siguientes áreas:

\section{Estudio transversal en ciudades de similar tamaño de población}

Si bien, la dificultad que considera referirse en general a seis áreas urbanas (y diez comunas) de escala intermedia con diversas complejidades sociales y territoriales, se ha hecho un esfuerzo para que el análisis específico y transversal de las ciudades intermedias entregue evidencias a través de similitudes y contrastes, que luego permitan generar políticas públicas homologables a dicha escala pre-metropolitana. Este ejercicio transversal podría desarrollarse no sólo en el ámbito de la SRS, sino que también en áreas como el medio ambiente, el riesgo, transporte, patrimonio y otros.

A su vez, la complementación de diversas investigaciones específicas al análisis cartográfico que se asume limitado, permitió entregar mayores antecedentes y conclusiones mayormente sólidas en cada caso de estudio, siendo fundamentales especialmente en los casos de Antofagasta, Temuco - Padre Las casas, Iquique - Alto Hospicio y La Serena - Coquimbo, donde las condiciones geográficas son el fenómeno de la SRS.

La urgencia de la segregación, la oportunidad de las ciudades intermedias

Un segundo aporte de este trabajo dice relación con profundizar la evidencia acerca del estado en que se encuentran las futuras ciudades de escala metropolitana del país, y el cada vez más disminuido margen de acción que tendrá el Estado para revertir la segregación socio residencial en proceso de agudización y réplica de los fenómenos similares ocurridos en las ciudades altamente segregadas de Santiago, Valparaíso y Concepción .

En este mismo sentido, es necesario reflexionar en torno a las medidas que se podrían tomar en estas ciudades con procesos semiconsolidados de segregación, por ejemplo: (1) desde la investigación y planificación es necesario entender las ciudades como sistemas o conurbaciones, y ya no como comunas separadas; (2) desde la administración territorial se hace necesario y urgente la creación de autoridades intermedias con atribuciones y recursos suficientes para intervenir en temas de vivienda y ciudad, estando aún pendiente el grado de injerencia en estos temas que tendrán las nuevas figuras de gobiernos metropolitanos creadas por la recientemente aprobada Ley de Regionalización de Chile (Ley 21.704/2018); y (3) desde las políticas públicas habitacionales y urbanas se requiere la generación de un marco normativo que permita no solo localizar mejor la vivienda de interés social en la ciudad, sino también que evite la autosegregación de los estratos altos.

\section{Una nueva mirada de la segregación socioeconómica a través de la homogeneidad}

Finalmente, a pesar del análisis unidimensional en base a características exclusivamente socioeconómicas y que ha sido explorada a nivel de manzana (podría trabajarse en el futura a nivel de unidades mayores), existe un avance en proponer una perspectiva de homogeneidad/heterogeneidad social que considere la concentración de grupos a través de diversos fenómenos y escalas cuantificables, que permitan entregar un nuevo elemento para diagnosticar y evaluar las consecuencias de la segregación residencial entendida como la fragmentación social y no sólo la concentración de los estratos más bajos.

La evidencia bibliográfica en general pone énfasis en cómo la segregación ha estado mayormente vinculada a los GSE más bajos, sin embargo, como se ha hecho explícito en este trabajo, tan importante como generar programas y políticas para disminuir dicha brecha en los sectores más empobrecidos, es también relevante considerar la planificación e intervención de las áreas que poseen mayores recursos y en acceso definitivo acceso a los beneficios de la ciudad. Asimismo, queda mucho por avanzar a una visión de homogeneidad que considera mayores dimensiones étnicas, socio-ocupacionales, etarias, raciales, de género, etc. (sobre todo si se considera la creciente tasa de inmigración) 


\section{Referencias}

Arancibia, A. (2014). Reducción de las escalas de segregación residencial, espacios urbanos de integración en el entorno de la población Santa Teresa, en la conurbación Machalí - Rancagua (Tesis para optar al Grado de Magister en Hábitat Residencial, Universidad de Chile, Santiago, Chile). Recuperada de http://repositorio.uchile.cl/handle/2250/130320

Arenas, F., González, D., y Aliaga, G. (2009). La conurbación Rancagua-Machalí: transformaciones socioespaciales de una ciudad media. En Hidalgo, R., de Mattos, C. y Arenas, F. (Eds.) Chile: del país urbano al país metropolitano, (pp. 347-358). Santiago: Pontificia Universidad Católica de Chile.

Atisba. (2010). Guetos en Chile. Reporte Noviembre 2010. Recuperado de http://atisba.cl/wpcontent/uploads/2011/10/Reporte Guetos en Chile 2010.pdf

Bermúdez. O. (1964). Historia del salitre desde sus orígenes hasta la guerra del pacífico. Santiago: Editorial universitaria.

Borsdorf, A., Sánchez, R., y Marchant, C. (2008). Aprendiendo de los errores: La necesidad de cambios a la política nacional de vivienda en ciudades intermedias chilenas. Scripta Nova: revista electrónica de geografía y ciencias sociales, 12, 47.

Borsdorf, A., Marchant, C. y Sánchez, R. (2012). Changes in urbanization processes. e intermediate cities in the Chilean urban system. En D. Rivera (Ed.), Chile: Environmental, political and social issues (pp. 159173). Nueva York: Nova Publishers.

Daher, A. (2003). Regiones-commodities: Crisis y contagio en Chile. EURE (Santiago), 29(86), 89-108. https://doi.org/10.4067/s0250-71612003008600005

Daher, A. (2016). Metropolización en la región de mayor crecimiento de Chile, Coquimbo. AUS (Valdivia), 19, 45-50. https://doi.org/10.4206/aus.2016.n19-08

Catalán Lizama, L. (2017). Segregación socio-residencial. Aproximaciones a un sistema de indicadores de medición social territorial. Revista de Urbanismo, 37, 1-12. https://doi.org/10.5354/0717-5051.2017.45131

CEPAL. (1998). Ciudades intermedias de América Latina y el Caribe: propuestas para la gestión urbana. Santiago: CEPAL.
Espinoza, D., Zumelzu, A., Burgos R. y Mawromatis, C. (2016). Transformaciones espaciales en ciudades intermedias: el caso de Valdivia-Chile y su evolución post-terremoto. Revista Arquitectura y Urbanismo, XXXVII (3), 1-22.

Garín A., Salvo S., y Bravo G. (2009). Segregación residencial y políticas de vivienda en Temuco: 1992 2002. Revista de Geografía Norte Grande, 44, 113-128. https://doi.org/10.4067/s0718-34022009000300006

Guerrero, B. (2007). La ciudad y sus transformaciones: memoria urbana de Iquique. Revista de Ciencias Sociales, 19, 149-165.

Hidalgo, R. (2007). ¿Se acabó el suelo en la gran ciudad?: Las nuevas periferias metropolitanas de la vivienda social en Santiago de Chile. EURE (Santiago), 33(98), 57-75. https://doi.org/10.4067/s025071612007000100004

Hidalgo, R., De Mattos, C. y Arenas, F. (2009). Chile: del país urbano al país metropolitano. Santiago: Pontificia Universidad Católica de Chile.

Instituto Nacional de Estadísticas. (2003). Censo 2002. Síntesis de resultados. Recuperado de http://www.ine.cl/cd2002/sintesiscensal.pdf

Inzulza-Contardo, J. (2014). La recuperación del diseño cívico como reconstrucción de lo local en la ciudad intermedia: el caso de Talca, Chile. AUS (Valdivia), 15, 4-8. https://doi.org/10.4206/aus.2014.n15-02

Labbé, G. (2014). Del gueto al hipergueto en el centro y pericentro de la ciudad de Iquique (Tesis para optar al título de Geógrafa, Universidad de Chile, Santiago, Chile). Recuperada de http://repositorio.uchile.cl/handle/2250/130081

Letelier, F. y Boyco, P. (2010). Los desafíos de la ciudad intermedia: entre el neoliberalismo y la política. En Varios autores (Eds.). Pensar la ciudad. Santiago: Ediciones SUR http://www.sitiosur.cl/r.php?id=928

Letelier, F. y Boyco, P. (2013). Talca a tres años del terremoto: aprendizajes colectivos para la acción en la ciudad. Temas Sociales, 70, 1-8. Recuperado de http://www.sitiosur.cl/r.php?id=933 
Link, F., Valenzuela, F., y Fuentes, L. (2015). Segregación, estructura y composición social del territorio metropolitano en Santiago de Chile: Complejidades metodológicas en el análisis de la diferenciación social en el espacio. Revista de geografía Norte Grande, 62, 151-168. $\quad$ https://doi.org/10.4067/s0718$\underline{34022015000300009}$

López-Morales, E. (2013). Gentrificación en Chile: aportes conceptuales y evidencias para una discusión necesaria. Revista de Geografía Norte Grande, 56, 3152.

https://doi.org/10.4067/s071834022013000300003

López-Morales, E. (2015). Suelo urbano y segregación residencial: hacia una agenda de integración social para zonas centrales metropolitanas chilenas. Ciudades, 18,197-213.

https://doi.org/10.24197/ciudades.18.2015.197-213

Maragaño A. (2009). La evolución temporal de las estructuras urbanas y la reconfiguración cívica de la ciudad. Sobre el centro urbano de la ciudad de Talca (1980-2007). En Hidalgo, R., de Mattos, C. y Arenas, F. (Eds.) Chile: del país urbano al país metropolitano, (pp. 359-387). Santiago: Pontificia Universidad Católica de Chile.

Marcuse, P. (1989). 'Dual City': a muddy metaphor for a quartered city. International journal of urban and regional research, 13(4), 697-708. https://doi.org/10.1111/j.1468-2427.1989.tb00142.x

Maturana, F. y Rojas, A. (2015). Ciudades intermedias en Chile. Territorios olvidados. Santiago de Chile: RIL Editores.

MINVU (2007). Análisis De Tendencias De Localización. Planes De Gestión Integrada Sistema Urbano La Serena Coquimbo. Santiago: MINVU.

ONU-Habitat. (2012). Estado de las ciudades de América Latina y el Caribe 2012. Rumbo a una nueva transición urbana. Recuperado de: http://cite. acsoandes.edu.ec/media/2016/02/

ONU Habitat 2012 Estado de las ciudades de America Latina y el Caribe. Rumbo a una nueva transicion urbana1. pdf

Orellana, A., Díaz, M. y Fierro, M. (2016). De ciudad Mediterránea a Metrópolis costera, El caso de la Gran Serena. Urbano, 33, 30 - 43.
Rodríguez, J., y Arriagada, C. (2004). Segregación Residencial en la Ciudad Latinoamericana. EURE (Santiago),30(89),5-24. https://doi.org/10.4067/s0250-71612004008900001

Rodríguez, A., y Sugranyes, A. (2005). Los con techo. Un desafío para la política de vivienda social. Santiago: SUR Ediciones.

Rodríguez, J., \& Winchester, L (2005). Metropolización, globalización, desigualdad. Revista EURE (Santiago), 27(80), 121-139. https://doi.org/10.4067/s025071612001008000006

Rodríguez, L., \& Carrasco, B. (2016). Lugares con sentido, identidad y teoría urbana: el caso de las ciudades de Concepción y Talca. Revista de Geografía Norte Grande, 64, 167-186. https://doi.org/10.4067/s071834022016000200011

Ruiz-Tagle, J. (2016). La segregación y la integración en la sociología urbana: revisión de enfoques y aproximaciones críticas para las políticas públicas. Revista INVI, 31(87), 9-57. https://doi.org/10.4067/s0718-83582016000200001

Ruiz-Tagle, J., \& López, E. (2014). El estudio de la segregación residencial en Santiago de Chile: revisión crítica de algunos problemas metodológicos y conceptuales. EURE (Santiago), 40(119), 25-48. https://doi.org/10.4067/s0250-71612014000100002

Ruiz-Tagle, J. (2013). A theory of socio-spatial integration: Problems, policies and concepts from a US perspective. International Journal of Urban and regional research, 37(2), 388-408. https://doi.org/10.1111/j.1468-2427.2012.01180.x

Sabatini, F. (2006). La segregación social del espacio en las ciudades de América Latina. Inter-American Development Bank.

Sabatini, F., y Brain, I. (2008). La segregación, los guetos y la integración social urbana: mitos y claves. EURE (Santiago), 34(103), 5-26. https://doi.org/10.4067/s0250-71612008000300001

Sabatini, F., Cáceres, G., y Cerda, J. (2001). Segregación residencial en las principales ciudades chilenas: Tendencias de las tres últimas décadas y posibles cursos de acción. EURE (Santiago), 27(82), 21-42. https://doi.org/10.4067/s0250-71612001008200002 
Sabatini, F., Mora, P., \& Polanco, I. (2013). Control de la segregación socio-espacial: Rebatiendo mitos, construyendo propuestas. Recuperado de: https://www.espaciopublico.cl/control-de-lasegregacion-socio-espacial-rebatiendo-mitosconstruyendo-propuestas/

Sabatini, F., Rasse, A., Mora, P., \& Brain, I. (2012). ¿Es posible la integración residencial en las ciudades chilenas?: Disposición de los grupos medios y altos a la integración con grupos de extracción popular. EURE (Santiago), 38(115), 159-194. https://doi.org/10.4067/s0250-71612012000300008

Sabatini, F., Rasse, A., Cáceres, G., Robles, M. S., \& Trebilcock, M. P. (2017). Promotores inmobiliarios, gentrificación y segregación residencial en Santiago de Chile. Revista mexicana de sociología, 79(2), 229-260.

Sabatini, F., Salcedo, R., Wormald, G., y Cáceres, G. (2010). Tendencias de la segregación en las principales ciudades chilenas: análisis censal 1982-2002. Santiago: Ediciones INE.

Salazar, G., Irarrázaval, F. y Fonck, M. (2017). Ciudades intermedias y gobiernos locales: desfases escalares en la Región de La Araucanía, Chile. EURE (Santiago), 43(130), 161-184. https://doi.org/10.4067/s0250$\underline{71612017000300161}$
Sassen, S. (1991). The global city: New York, London and Tokyo. New Jersey: Princeton University Press.

Smith, N. (1996). The New Urban Frontier. Gentrification and the Revanchist. New York: Routledge.

Tapia Zarricueta, R. (2011). Vivienda social en Santiago de Chile. Análisis de su comportamiento locacional, período 1980- 2002. Revista INVI, 26(73), 105-131. https://doi.org/10.4067/s0718-83582011000300004

Thodes Miranda, E. (2016). Segregación socioespacial en ciudades mineras: el caso de.Antofagasta, Chile. Notas de población, 43(102), 203-227. Recuperado de: http://repositorio.cepal.org/handle/11362/40265

Toro, F. (2014). Conjunto de integración y mixtura social en el centro de La Serena. (Memoria para optar al título de Arquitecto, Universidad de Chile, Santiago, Chile). Recuperada de http://repositorio.uchile.cl/handle/2250/130051

Wormald, G., Flores, C., Sabatini, F., Trebilcock, M., y Rasse Figueroa, A. (2012). Cultura de cohesión e integración en las ciudades chilenas. Revista INVI, 27(76), 117-145. https://doi.org/10.4067/s0718-83582012000300004 